\title{
Emergent opportunities in humans: playful kittens, an arthropod vector, and a zoonotic agent
}

\author{
Cathleen A. Hanlon ${ }^{\mathrm{a}}$, Robert E. Dedmon ${ }^{\mathrm{b}}$ \\ aKansas State University Rabies Laboratory, College of Veterinary Medicine, 2005 Research Park \\ Circle, Manhattan, KS 66502; ' Department of Population Health, Medical College of Wisconsin, \\ Milwaukee 53226, USA
}

\begin{abstract}
Bartonella henselae is implicated as the main etiologic agent of Cat scratch disease (CSD, Cat-scratch fever). A majority of domestic cats may harbor the intra-erythrocytic agent for extended periods without apparent disease. In humans, $B$. henselae most commonly results in a subacute, bacterial infection that presents with one or more reddish papules which may progress to pustules and regional lymph node enlargement. Usual features include fever, malaise, and a granulomatous lymphadenitis on biopsy. However, atypical clinical presentations occur, albeit with infrequence, and may result in a difficult and protracted diagnostic process. The infection in susceptible hosts such as immunocompromised or elderly patients may result in endocarditis, encephalitis, fever of unknown origin, and general malaise. It is not transmitted from person to person and quarantine is not necessary. The arthropod vector, Ctenocephalides felis, or the cat flea, plays a major role in transmission among cats and to humans. The transmission risk to humans can be substantially reduced through elimination of flea infestations in companion animals. There are numerous recent reviews and case reports in the veterinary and medical literature reflecting increased recognition of this zoonotic agent. All this notwithstanding, many physicians and other providers may not be familiar with this agent and the potential spectrum of human disease; this may lead to delays in diagnosis and unnecessary diagnostic procedures. This article emphasizes the aspects of $B$. henselae infection, including a typical case report and a table with selected human case reports of unusual clinical manifestations from the published literature.
\end{abstract}

Keywords: Bartonella henselae, cat scratch disease, zoonosis

The first description of a clinical syndrome involving localized lymphadenopathy occurred in the French literature by Henri Parinaud in 1889 [1]. In 1931, Dr. Robert Debré coined the term "Cat Scratch Disease" to describe the syndrome and associated epidemiologic characteristics [2]. Since then, the disease has been shown to occur globally and increasingly important as a zoonosis (diseases transmitted from animals to humans) [3-8]. Zoonoses have been estimated to cause over $60 \%$ of emerging infectious disease in the past 50 years (e.g. rabies, ebola, pulmonary hantavirus syndrome, New-variant

Correspondence to: Cathleen A. Hanlon, VMD PhD, Director, Kansas State University Rabies Laboratory, College of Veterinary Medicine, 2005 Research Park Circle, Manhattan, KS 66502, USA. E-mail: chanlon@vet.ksu.edu
Creutzfeldt-Jakob disease, etc.) [9]. Professor Frederick Murphy of the School of Veterinary Medicine, University of California, commented on the unique nature of zoonoses, the challenges of funding, and research infrastructure, and the need for research for strategies of prevention and control [10]. Moreover, diagnosis and prevention of zoonotic diseases requires collaboration among diverse professionals in the medical, veterinary, research and public health arenas.

In this article, in addition to the case report below, we provide a brief overview of agent, occurrence, reservoir, vector, clinical presentation, transmission, diagnosis, prevention, and a table with selected case reports from the published literature underscoring the multiple potential clinical presentations of CSD in humans. 


\section{Case report from Bangkok*}

A48-year-old healthy bachelor American engineer working in Myanmar (Burma) was referred to a Bangkok hospital for evaluation of low grade fever, malaise, anorexia, headaches of two weeks duration and for biopsy of a persistently enlarged lymph node in his axilla. He had been treated with an unknown "broad spectrum" antibiotic by a local physician who reported normal complete blood counts and an aspiration of the node that was negative for microorganisms by acid-fast bacilli and Gram stains.

Physical examination on admission revealed normal temperature and vital signs. The patient's right axillary lymph node was tender and slightly enlarged measuring approximately two centimeters in diameter. There were no other abnormal physical findings. The complete blood count, urinalysis, aspartate aminotransferase, adenylate kinase, blood glucose, and chest X-ray were normal. A tuberculin skin test was negative. His erythrocyte sedimentation rate was 58 . A surgeon performed an incisional biopsy of the enlarged node, which yielded negative acid-fast bacillus (AFB) and Gram stains. A later culture grew no bacteria and an AFB culture was not done. An infectious disease consultant was asked to see the patient, who reported extensive sexual contacts with different partners. Lymphogranuloma venereum had been diagnosed in one of his contacts. A more detailed history then revealed that he had acquired a kitten shortly before his illness and that after playing with it, he had noted a papule on his right index finger that persisted for about one week before he first noted fever, headaches and about one week later the enlarging lymph node. A presumptive diagnosis of Cat Scratch Disease was then made, he was started on doxycycline $100 \mathrm{mg}$ twice daily (even though he had already improved considerably), and serum was sent to the London School of Tropical Medicine which later returned a negative serology report.

At the time of clinical illness in the mid 1990's, no PCR or other serologic tests were available in Bangkok or Singapore. The patient returned to Myanmar with a two weeks empirical course of doxycycline. Consultants from the veterinary faculty in Bangkok recommended that he treat his kitten with a flea insecticide and tetracycline for 10 days. The patient reported one month later that his enlarged lymph node had resolved and that he had fully recovered. $\mathrm{He}$ managed his cat, which had always appeared healthy, as recommended. No other person in his household had any similar illness.

\section{Agent}

Bartonella species are important emerging zoonotic agents [3, 5, 8, 11]. The genus Bartonella includes at least 24 species or sub-species, of which half have been described to be responsible for human disease [12]. Bartonella species are small, fastidious, intracellular gram-negative bacilli that are aerobic and oxidase-negative. The organisms are most easily visualized by using a Warthin-Starry silver impregnation stain (Fig. 1) or a Brown-Hopps tissue Gram-stain [13]. At least, five species are associated with cats, most often with a subclinical occurrence. In addition

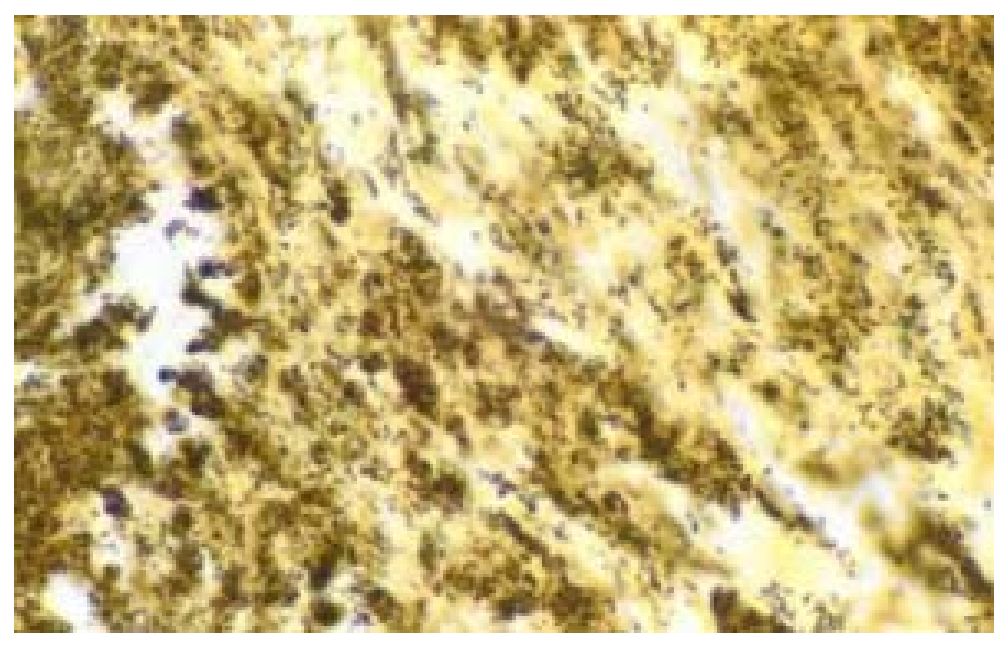

Fig. 1 Demonstration of Bartonella henselae in cardiac valve of a patient with blood-culture-negative endocarditis. The bacilli appear as black granulations (Warthin-Starry stain). Source-CDC/EID February 2002;8(2).

*This case report was provided by Professor Wilde H, Chulalongkorn University. 
to cats, numerous wild and domestic species can serve as chronically infected reservoir hosts for various species of Bartonella [11]. Bartonella henselae is implicated as the main etiologic agent of Cat scratch disease (CSD, Cat-scratch fever) [11]. Two main genogroups of $B$. henselae have been identified in humans and cats: Houston-1 and Marseille (also known as genotype II) [14]. These two genogroups are further subdivided into four variants: Marseille, CAL-1, Houston-1, and ZF-1 [15-17].

\section{Occurrence}

Bartonella species occur worldwide and may result in a variety of clinical presentations in humans. Recently, there may be increased recognition of clinical syndromes associated with these pathogens $[7,18]$.

\section{Reservoir}

Cats are the major reservoir for $B$. henselae. In populations of domestic cats throughout the world, seroprevalence surveys indicate that substantial proportions appear to have been exposed to Bartonella spp [19, 20]. Bacteremia is more likely in younger cats and seropositivity is more likely in older cats $[11,19] . B$. henselae infection in cats is typically subclinical or non-specific and mild, and may not be obvious to the pet owner. Fever and lymphadenopathy may occur. Lymphadenopathy can be local or generalized and long-standing, lasting a month or more. When infection is coincident with other agents such as feline immunodeficiency, it is associated with the presence of more prominent clinical disease, such as uveitis, stomatitis, urinary tract disorders, and neurologic disease $[21,22]$. The spectrum of clinical illness remains in need of elucidation, as evidenced by at least one case of vegetative aortic valve endocarditis due to $\mathrm{B}$. henselae that was culturenegative but fatal [23].

Treatment of cats with antibiotics can reduce bacteremia, but recrudescence may occur and cats are still subject to re-infection [24]. Antibiotic treatment should be reserved for clinically ill cats where there is a definitive diagnosis or a high index of suspicion [25]. Diagnostic confirmation can be difficult. In sick cats, culture of blood or tissue biopsy is reliable but not always sensitive. Depending upon the molecular approach and laboratory expertise, PCR, nested PCR or real-time PCR may equal or exceed culture in diagnostic sensitivity. Serologic techniques are most useful for population surveys, rather than for diagnosis of acute infection, as antibodies persist beyond active infection. Indirect fluorescent antibody, enzyme immunoassay, and Western blot tests may be useful, but depending upon the source of antigen and the genetic diversity of the Bartonella sp. in an individual or population, the tests may have limited sensitivity.

Comprehensive vector control (i.e., flea control for animals and environmental management of the home) and client education should always be implemented when antibiotic treatment is instituted, as the most reliable management tool for prevention of infection (or re-infection) of pets and humans is flea control.

\section{Vector}

The arthropod vector, Ctenocephalides felis, or the cat flea, plays a major role in transmission among cats and to humans [26]. Human infection can be prevented through elimination of flea infestations $[8,27,28]$

\section{Clinical presentation}

In humans, $B$. henselae most commonly results in a subacute, bacterial infection which presents with one or more reddish papules which may progress to pustules (Fig. 2) and regional lymph node enlargement [6]. Usual features include fever, malaise, and a granulomatous lymphadenitis on biopsy. However, atypical clinical presentations occur, albeit with infrequence, and may result in a difficult and protracted diagnostic process. These infrequent clinical presentations may include lesions suggestive of malignancy (e.g. lymphoma) or other infectious processes such as tuberculosis, brucellosis, tularemia, and plague [29]. Other clinical presentations include optic neuritis, osteomyelitis, encephalitis, and the Parinaud oculoglandular syndrome (Unilateral conjunctivitis with associated pre-auricular lymphadenopathy) [30-50]. In susceptible hosts such as immunocompromised or elderly patients, the infection may result in endocarditis, encephalitis, fever of unknown origin, and general malaise - the hallmark lymphadenitis characteristic in younger patients is often absent [51]. Submandibular swelling and a presumed dental abscess may lead to clinical recognition of the infection upon presentation to a dentist rather than to a physician [52]. Other reported manifestations include hepatitis and pneumonia [53-55]. 


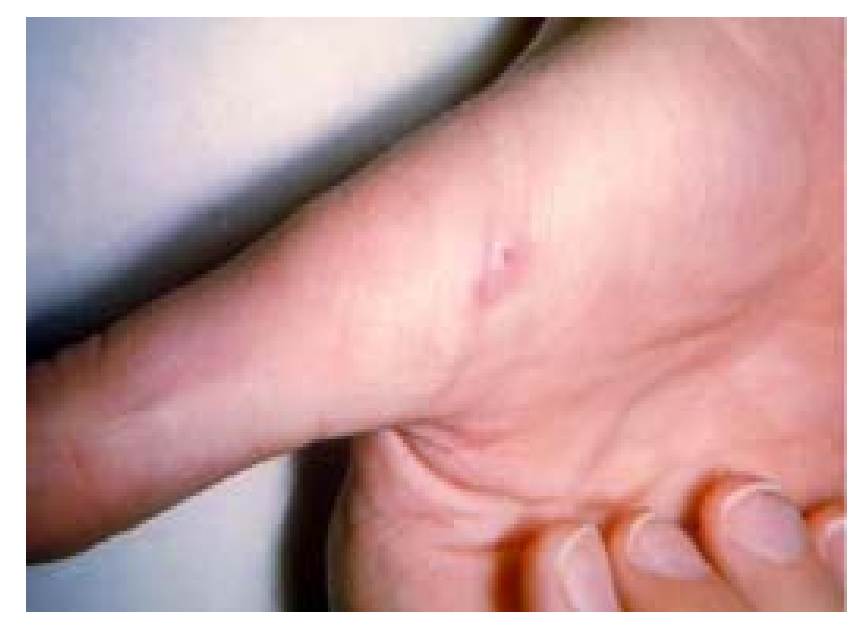

Fig. 2 Cat Scratch lesion on thumb. Source: CDC's Public Health Image Library (http://phil.cdc.gov/public/1269.htm).

The response to infection with $B$. henselae depends on the immune status of the infected host. In immunocompetent humans, the response is granulomatous and suppurative, as compared with a vasoproliferative response in immunocompromised patients [14, 29]. In an immunocompetent patient, lymphoid hyperplasia, arteriolar proliferation, and widened arteriolar walls progress to granulomatous disease and stellate microabscesses.

Immunodeficient patients are at risk for bacillary angiomatosis (Fig. 3), which manifests as cutaneous angiogenic lesions [56]. These lesions consist of vascular proliferation composed of endothelial cells and a mixed inflammatory cell infiltrate. The mechanism by which $B$ henselae induces angiogenesis is not fully understood. One hypothesis is that
Bartonella modulates host or target cell cytokines and growth factors, which lead to angiogenesis.

\section{Transmission}

B. henselae is not transmitted from person to person and quarantine is not necessary. Although the exact mode of transmission from cats to humans is unclear, it is generally accepted that the infectious agent is inoculated when human skin is scarified by the claws or teeth of a cat contaminated with infected flea feces or through direct contact of conjunctival membranes, with infected feces [14, 26, 57]. This mode of transmission is similar to that of $B$. quintana to humans which also relies upon mechanical transmission through infected arthropod feces, with B. Quintana most commonly from the human body louse.

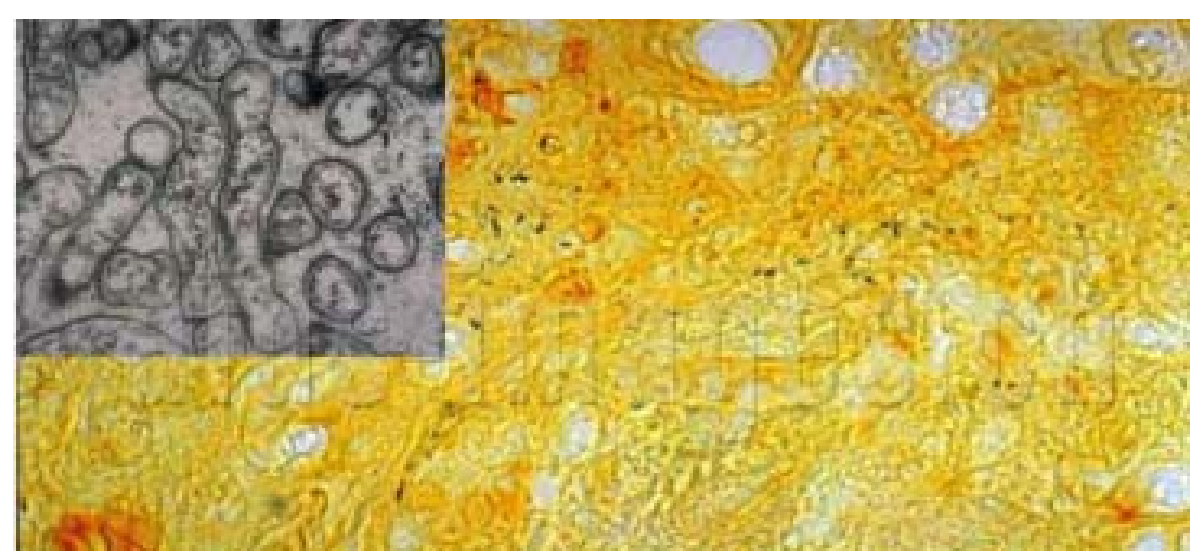

Fig. 3 Bacillary angiomatosis due to Bartonella. henselae in HIV-AIDS patient (Biopsy: Whartin-Starry stain. Insert: electron microscopy). B. henselae shows up black red-like or coccobacillary elements. Definitte diagnosis relies on amplification and sequencing of 16rDNA as well as serology. Image courtesy of Aids Images Library (www.aidsimages.ch). 


\section{Diagnosis}

A definitive diagnosis may involve a combination of clinical, epidemiologic, serologic, histologic, and molecular criteria $[6,58]$. A presumptive diagnosis is often based on history and clinical criteria: contact with a cat, patient-reported presumed site of inoculation resulting from a scratch or bite to the skin or primary lesion of eye or mucous membrane, and a subsequent regional lymphadenopathy. At this time, there is no single criterion that can be considered the diagnostic gold standard for $B$. henselae. Recent diagnostic investigation supports the usefulness of testing for $B$. henselae DNA by PCR analysis in patients with an isolated superficial lymphadenopathy [59]. With a positive PCR result, the diagnosis of CSD can be confirmed with excellent specificity. If there is a negative result, the diagnosis would rely upon at least two of the following: (i) positive serology, (ii) histology compatible with CSD (pyogenic granuloma), or (iii) contact with cats during the days or weeks preceding lymphadenopathy, together with elimination of other causes of lymph node enlargement.

\section{Prevention}

There is strong evidence that spread of infection between cats depends on the arthropod vector
Ctenocephalides felis, or the cat flea [14, 57]. Elimination of arthropod infestation in the pet, especially flea infestation, is often successful in disrupting the transmission cycle both cat-to-cat and cat-to-human.

\section{Conclusion}

There are numerous recent reviews and case reports in the veterinary and medical literature reflecting increased recognition of this zoonotic agent [3-8]. The 2009 online version of the American Academy of Pediatrics Red Book has several excellent clinical images of patients with CSD [60]. All this notwithstanding, many physicians and other providers may not be familiar with this disease; this may lead to delays in diagnosis and unnecessary diagnostic procedures. As part of a complete history for all patients, healthcare providers should actively elicit information about pets and other potential animal contact. Early serologic and molecular testing for CSD may be particularly useful for the pediatric patient to avoid unnecessary interventions and to expedite appropriate medical management [37, 57]. With reasonable precautions, even immunocompromised patients may still enjoy the benefits of the humananimal bond, including one with young cats [61].

\section{Appendix. Unusual cases in humans}

\section{Patients}

51-year-old female

Six school-aged patients

Four acquired

immunodeficiency syndrome

(AIDS) patients

3 HIV-positive patients

40-year-old male with AIDS
Unusual cases

Cervical lymphadenopathy; contact with domestic dog

Osteomyelitis; dog scratch

Inguinal lymphadenopathy, and osteomyelitis; exposure to kittens.

Multifocal osteomyelitis

Vertebral osteomyelitis; multiple cat scratches

Meningo-encephalitis

Hemiplegia.

Anatomic diagnosis; hepatitis caused by Bartonell henselae contact with cats

Lymphadenopathy of hepatic hilum

Status epilepticus.

Angiomatous nodules; 2 with history of cat scratch

Ocular lesions (sub-retinal masses and abnormal vascular network)

Epithelioid angiomatosis, disseminated; cat scratch
Authors

Da Silva and Chussid, 2009 [62]

Keret et al.,1998 [63]

Rozmanic et al., 2007 [64]

De Kort et al., 2006 [65]

Robson et al., 1999 [66]

Cherinet and Tomlinson, 2008 [67]

Rocha et al., 2004 [68]

Pelton et al., 2006 [69]

Imperiale et al., 2008 [53]

Armengol and Hendley, 1999 [70]

Koehler et al., 1988 [56]

Curi et al., 2006 [71]

Milam et al., 1990 [72] 


\section{Acknowledgment}

The authors have no conflict of interest to report.

The first author $(\mathrm{CAH})$ provided information on occurrence of Bartonella henselae in cats, wrote a major part of the paper, and edited the final version. The last author (RED) researched the literature and summarized case reports from the published literature, as well as a case provided by a colleague. $\mathrm{He}$ also wrote part of the paper and reviewed the manuscript.

\section{References}

1. Moriarty RA, Margileth AM. Cat scratch disease. Infect Dis Clin North Am. 1987; 1:575-90.

2. Debre R, Lamy M, Jammet ML, Costil L, Mozziconacci P. Cat scratch disease. Sem Hop. 1950; 26:1895-904.

3. Boulouis HJ, Chang CC, Henn JB, Kasten RW, Chomel BB. Factors associated with the rapid emergence of zoonotic Bartonella infections. Vet Res. 2005; 36: $383-410$.

4. Chomel BB, Boulouis HJ, Breitschwerdt EB. Cat scratch disease and other zoonotic Bartonella infections. J Am Vet Med Assoc. 2004; 224:1270-9.

5. Comer JA, Paddock CD, Childs JE. Urban zoonoses caused by Bartonella, Coxiella, Ehrlichia, and Rickettsia species. Vector Borne Zoonotic Dis. 2001; 1:91-118.

6. Florin TA, Zaoutis TE, Zaoutis LB. Beyond cat scratch disease: widening spectrum of Bartonella henselae infection. Pediatrics. 2008; 121:e1413-25.

7. Mogollon-Pasapera E, Otvos L Jr, Giordano A, Cassone M. Bartonella: emerging pathogen or emerging awareness? Int J Infect Dis. 2009; 13:3-8.

8. Saisongkorh W, Rolain JM, Suputtamongkol Y, Raoult D. Emerging Bartonella in humans and animals in Asia and Australia. J Med Assoc Thai. 2009; 92:707-731.

9. Jones KE, Patel NG, Levy MA, Storeygard A, Balk D, Gittleman JL, et al. Global trends in emerging infectious diseases. Nature. 2008; 451:990-3.

10. Murphy FA. Emerging zoonoses. Emerg Infect Dis. 1998; 4:429-35.

11. Breitschwerdt EB, Kordick DL. Bartonella infection in animals: carriership, reservoir potential, pathogenicity, and zoonotic potential for human infection. Clin Microbiol Rev. 2000; 13:428-38.

12. Vayssier-Taussat M, Le Rhun D, Bonnet S, Cotte V. Insights in Bartonella host specificity. Ann N Y Acad Sci. 2009; 1166:127-32.

13. Kudo E, Sakaki A, Sumitomo M, Fujii Y, Hirose T, Sano $\mathrm{T}$, et al. Cat scratch disease. An epidemiological and ultrastructural study of lymphadenitis caused by
Warthin-Starry positive bacteria. Virchows Arch A Pathol Anat Histopathol. 1988; 412:563-72.

14. Regnery R, Tappero J. Unraveling mysteries associated with cat-scratch disease, bacillary angiomatosis, and related syndromes. Emerg Infect Dis. 1995; 1:16-21.

15. Ehrenborg C, Wesslen L, Jakobson A, Friman G, Holmberg M. Sequence variation in the fts $Z$ gene of Bartonella henselae isolates and clinical samples. J Clin Microbiol. 2000; 38:682-7.

16. Arvand M, Schubert H, Viezens J. Emergence of distinct genetic variants in the population of primary Bartonella henselae isolates. Microbes Infect. 2006; 8: 1315-20

17. Berghoff J, Viezens J, Guptill L, Fabbi M, Arvand M. Bartonella henselae exists as a mosaic of different genetic variants in the infected host. Microbiology. 2007, 153:2045-51.

18. Breitschwerdt EB, Maggi RG, Cadenas MB, de Paiva Diniz PP. A groundhog, a novel Bartonella sequence, and my father's death. Emerg Infect Dis. 2009; 15: 2080-6.

19. Chomel BB, Abbott RC, Kasten RW, Floyd-Hawkins KA, Kass PH, Glaser CA, et al. Bartonella henselae prevalence in domestic cats in California: risk factors and association between bacteremia and antibody titers. J Clin Microbiol. 1995; 33:2445-50.

20. Kelly PJ, Matthewman LA, Hayter D, Downey S, Wray K, Bryson NR, et al. Bartonella (Rochalimaea) henselae in southern Africa - evidence for infections in domestic cats and implications for veterinarians. J S Afr Vet Assoc. 1996; 67:182-7.

21. Glaus T, Hofmann-Lehmann R, Greene C, Glaus B, Wolfensberger C, Lutz H. Seroprevalence of Bartonella henselae infection and correlation with disease status in cats in Switzerland. J Clin Microbiol. 1997; 35: 2883-5.

22. Ueno H, Hohdatsu T, Muramatsu Y, Koyama H, Morita C. Does coinfection of Bartonella henselae and FIV induce clinical disorders in cats? Microbiol Immunol. 1996; 40:617-20.

23. Chomel BB, Wey AC, Kasten RW, Stacy BA, Labelle P. Fatal case of endocarditis associated with Bartonella henselae type I infection in a domestic cat. J Clin Microbiol. 2003; 41:5337-9.

24. Greene CE, McDermott M, Jameson PH, Atkins CL, Marks AM. Bartonella henselae infection in cats: evaluation during primary infection, treatment, and rechallenge infection. J Clin Microbiol. 1996; 34: 1682-5.

25. Brunt J, Guptill L, Kordick DL, Kudrak S, Lappin MR. 
American Association of Feline Practitioners 2006 Panel report on diagnosis, treatment, and prevention of Bartonella spp. infections. J Feline Med Surg. 2006; 8:213-26.

26. Chomel BB, Kasten RW, Floyd-Hawkins K, Chi B, Yamamoto K, Roberts-Wilson J, et al. Experimental transmission of Bartonella henselae by the cat flea. J Clin Microbiol. 1996; 34:1952-6.

27. Breitschwerdt EB. Feline bartonellosis and cat scratch disease. Vet Immunol Immunopathol. 2008;123:167-71.

28. Koehler JE, Glaser CA, Tappero JW. Rochalimaea henselae infection. A new zoonosis with the domestic cat as reservoir. JAMA. 1994; 271:531-5.

29. Raoult D. From Cat scratch disease to Bartonella henselae infection. Clin Infect Dis. 2007; 45:1541-2.

30. Wong TZ, Kruskal J, Kane RA, Trey G. Cat-scratch disease simulating lymphoma. J Comput Assist Tomogr. 1996;20:165-6.

31. Wong MT, Dolan MJ, Lattuada CP, Jr. et al. Neuroretinitis, aseptic meningitis, and lymphadenitis associated with Bartonella (Rochalimaea) henselae infection in immunocompetent patients and patients infected with human immunodeficiency virus type 1 . Clin Infect Dis.1995; 21:352-60.

32. Woestyn S, Moreau M, Munting E, Bigaignon G, Delmee M. Osteomyelitis caused by Bartonella henselae genotype I in an immunocompetent adult woman. J Clin Microbiol. 2003; 41:3430-2.

33. Walsh LJ, Tuffley M, Young WG. An unusual dental presentation of cat scratch disease. Aust Dent J. 1985; 30:29-32.

34. van der Veer-Meerkerk M, van Zaanen HC. Visceral involvement in an immunocompetent male: a rare presentation of cat scratch disease. Neth J Med. 2008; 66:160-2.

35. Tsuneoka H, Tsukahara M. Analysis of data in 30 patients with cat scratch disease without lymphadenopathy. J Infect Chemother. 2006; 12:224-6.

36. Ridder GJ, Technau-Ihling K, Sander A, Boedeker CC. Spectrum and management of deep neck space infections: an 8-year experience of 234 cases. Otolaryngol Head Neck Surg. 2005; 133:709-14.

37. Reynolds MG, Holman RC, Curns AT, O’Reilly M, McQuiston JH, Steiner CA. Epidemiology of catscratch disease hospitalizations among children in the United States. Pediatr Infect Dis J. 2005; 24:700-4.

38. Pipili C, Katsogridakis K, Cholongitas E. Myocarditis due to Bartonella henselae. South Med J. 2008; 101: 1186.

39. Marsilia GM, La MA, Galdiero R, Galdiero E, Aloj G,
Ragozzino A. Isolated hepatic involvement of cat scratch disease in immunocompetent adults: Enhanced magnetic resonance imaging, pathological findings, and molecular analysis - two cases. Int J Surg Pathol. 2006; 14:349-54.

40. Margileth AM, Wear DJ, English CK. Systemic cat scratch disease: report of 23 patients with prolonged or recurrent severe bacterial infection. J Infect Dis. 1987; 155:390-402.

41. Margileth AM. Cat scratch disease: nonbacterial regional lymphadenitis. The study of 145 patients and a review of the literature. Pediatrics. 1968; 42:803-18.

42. Lewis P, Glaser CA. Encephalitis. Pediatr Rev. 2005; 26:353-63.

43. Lewis DW, Tucker SH. Central nervous system involvement in cat scratch disease. Pediatrics. 1986; 77:714-21.

44. Hagley M, Carne CA, Gorgees N. A case of cat scratch disease masquerading as lymphogranuloma venereum. Int J STD AIDS. 1999; 10:334-5.

45. Hadley S, Albrecht MA, Tarsy D. Cat-scratch encephalopathy: a cause of status epilepticus and coma in a healthy young adult. Neurology. 1995; 45 : 196.

46. Gouriet F, Lepidi H, Habib G, Collart F, Raoult D. From cat scratch disease to endocarditis, the possible natural history of Bartonella henselae infection. BMC Infect Dis. 2007; 7:30.

47. Gaubitz M, Herrmann M, Shahin M, Schotte H, Willeke P, Domschke W. Cat scratch disease (bartonellosis) mimicking an SLE flare. Lupus. 2001; 10:883-5.

48. Gamblin TC, Nobles-James C, Bradley RA, Katner HP, Dale PS. Cat scratch disease presenting as breast mastitis. Can J Surg. 2005; 48:254-5.

49. Gair DR, Wallis WL. Encephalitis in cat scratch disease; report of two cases. J Fla Med Assoc. 1957; 44:491-2.

50. Rocha JL, Pellegrino LN, Riella LV, Martins LT. Acute hemiplegia associated with cat-scratch disease. Braz J Infect Dis. 2004; 8:263-6.

51. Ben-Ami R, Ephros M, Avidor B, Ben-Ami R, Ephros M, Avidor B, Katchman E, Varon M, Leibowitz C, et al. Cat-scratch disease in elderly patients. Clin Infect Dis. 2005;41:969-74.

52. Mandel L, Surattanont F, Miremadi R. Cat-scratch disease: considerations for dentistry. J Am Dent Assoc. 2001; 132:911-4.

53. Imperiale $\mathrm{A}$, Blondet $\mathrm{C}$, Ben-Sellem $\mathrm{D}$, Forestier $\mathrm{E}$, Mohseni M, Piemont Y, et al. Unusual abdominal localization of cat scratch disease mimicking malignancy on F-18 FDG PET/CT examination. Clin Nucl 
Med. 2008; 33:621-3.

54. Incandela S, Raoult D, Vitale G, Micalizzi A, Mansueto P. Hepatosplenic cat-scratch fever with seropositivity for Bartonella quintana? Lancet Infect Dis. 2008; 8: 663.

55. Abbasi S, Chesney PJ. Pulmonary manifestations of cat-scratch disease; a case report and review of the literature. Pediatr Infect Dis J. 1995; 14:547-8.

56. Koehler JE, LeBoit PE, Egbert BM, Berger TG. Cutaneous vascular lesions and disseminated catscratch disease in patients with the acquired immunodeficiency syndrome (AIDS) and AIDS-related complex. Ann Intern Med. 1988; 109:449-55.

57. Zangwill KM, Hamilton DH, Perkins BA, Regnery RL, Plikaytis BD, Hadler JL, et al. Cat scratch disease in Connecticut. Epidemiology, risk factors, and evaluation of a new diagnostic test. N Engl J Med. 1993; 329: 8-13.

58. Rolain JM, Lepidi H, Zanaret M, Triglia JM, Michel G, Thomas PA, et al. Lymph node biopsy specimens and diagnosis of cat-scratch disease. Emerg Infect Dis. 2006; 12:1338-44.

59. Hansmann Y, DeMartino S, Piémont Y, Meyer N, Mariet P, Heller R, et al. Diagnosis of cat scratch disease with detection of Bartonella henselae by PCR: a study of patients with lymph node enlargement. J Clin Microbiol. 2005; 43:3800-6.

60. American Academy of Pediatrics. Redbook/Image Library. http://aapredbook.aappublications.org Accessed 21JUL2009. 2009.

61. Hemsworth S, Pizer B. Pet ownership in immunocompromised children: a review of the literature and survey of existing guidelines. Eur J Oncol Nurs. 2006; 10:117-27.

62. Da SK, Chussid S. Cat scratch disease: clinical considerations for the pediatric dentist. Pediatr Dent. 2009; 31:58-62.

63. Keret D, Giladi M, Kletter Y, Wientroub S. Cat-scratch disease osteomyelitis from a dog scratch. J Bone Joint Surg Br. 1998; 80:766-7.

64. Rozmanic V, Banac S, Miletic D, Manestar K, Kamber $\mathrm{S}$, Paparic S. Role of magnetic resonance imaging and scintigraphy in the diagnosis and follow-up of osteomyelitis in cat-scratch disease. J Paediatr Child Health. 2007; 43:568-70.

65. de Kort JG, Robben SG, Schrander JJ, van Rhijn LW. Multifocal osteomyelitis in a child: a rare manifestation of cat scratch disease: a case report and systematic review of the literature. J Pediatr Orthop B. 2006; 15 : 285-8.

66. Robson JM, Harte GJ, Osborne DR, McCormack JG. Cat-scratch disease with paravertebral mass and osteomyelitis. Clin Infect Dis. 1999; 28:274-8.

67. Cherinet Y, Tomlinson R. Cat scratch disease presenting as acute encephalopathy. Emerg Med J. 2008; 25: 703-4.

68. Rocha JL, Pellegrino LN, Riella LV, Martins LT. Acute hemiplegia associated with cat-scratch disease. Braz J Infect Dis. 2004; 8:263-6.

69. Pelton SI, Kim JY, Kradin RL. Case records of the Massachusetts General Hospital. Case 27-2006. A 17-year-old boy with fever and lesions in the liver and spleen. N Engl J Med. 2006; 355:941-8.

70. Armengol CE, Hendley JO. Cat-scratch disease encephalopathy: a cause of status epilepticus in school-aged children. J Pediatr .1999; 134:635-8.

71. Curi AL, Machado DO, Heringer G, Campos WR, Orefice F. Ocular manifestation of cat-scratch disease in HIV-positive patients. Am J Ophthalmol. 2006; 141: 400-1.

72. Milam MW, Balerdi MJ, Toney JF, Foulis PR, Milam $\mathrm{CP}$, Behnke RH. Epithelioid angiomatosis secondary to disseminated cat scratch disease involving the bone marrow and skin in a patient with acquired immune deficiency syndrome: a case report. Am J Med. 1990; 88:180-3. 